\title{
Educação integral e a perspectiva histórico-crítica: aproximações possíveis
}

Integral education and historical-critical perspective: possible approaches

\author{
Rita de Cássia Ventura Pattaro* \\ Colégio Meta, São Paulo
}

Vera Lúcia de Carvalho Machado**

Pontifícia Universidade Católica de Campinas

Resumo Considerando a importância da concepção e da prática de educação integral na história da educação brasileira, torna-se essencial entendê-la em sua plenitude para compreender suas proposições e de que maneira elas contribuem para a mudança social, brm como para uma formação completa das novas gerações. Por isso, este texto objetiva compreender as aproximações possíveis entre a concepção de educação integral e a perspectiva histórico-crítica, desenvolvida pelo educador Dermeval Saviani, correlacionando ambas com a jornada escolar ampliada. Foi utilizada a metodologia de pesquisa bibliográfica para a análise de uma teoria que é produto de reflexões e discussões com autores que se aproximam por terem o mesmo ideal de educação integral. Espera-se contribuir para as discussões sobre a implementação da política educacional de educação integral em tempo integral, balizadas pela perspectiva histórico-crítica.

PALAVRAS-CHAVE: Educação integral, Pedagogia histórico-crítica, Ampliação de jornada escolar.

Abstract Considering the importance of the theoretical assumptions that underlie the practice of integral education inside the history of Brazilian education, it is essential to comprehend it in its entirety to understand its proposals and how they contribute to social change and to a complete formation of new generations. Therefore, this paper aims to understand the possible approaches between the concept of integral education and the historical-critical perspective developed by the educator Dermeval Saviani, correlating both with the extended school day. It was used the literature research to do an analysis of a theory developed by authors who approach themselves by having the same ideal of integral education. It was expected to contribute to discussions on the implementation of educational policy of integral education in a full time, buoyed by historical-critical perspective.

KEYWORDS: Integral education, Historical-critical pedagogy, Extended school day. 


\section{Introdução}

Este texto discute a educação como atividade intencional marcada pelas práticas sociais, características de um determinado contexto e responsável pela socialização dos saberes construídos e acumulados historicamente, pelas gerações mais novas, que os transformarão em prol das necessidades de seu próprio tempo e espaço. Destaca que essa assunção de educação pressupõe o homem como um ser constituído por multidimensões que compõem sua integralidade. Desta forma, assume a perspectiva da educação integral como aquela que se aproxima desses ideais.

A proposição desse modelo educacional perpassa momentos importantes da história humana em diversos contextos sociais. A influência dessas ideias contribuiu (e ainda contribui) para discussões fundamentais que serviram (e ainda servem) ao propósito de elaboração de políticas educacionais propagadoras de uma educação integral.

A educação integral assume por completo a formação humana, tendo como meta abranger todas as dimensões que compõem a vida do ser social, que está situado em um contexto sócio-histórico, imerso no acervo cultural produzido ao longo do tempo pela humanidade e deixado, como herança, para as novas gerações. Essa base da educação integral assenta-se em diversos movimentos educacionais ao longo da História da Educação Brasileira, que, embora tenham em seus ideais, algumas concepções que difiram de um para o outro, entendem que a educação integral é o modelo que mais se aproxima do desenvolvimento completo do ser humano multidimensional.

Dentre as perspectivas educacionais, entende-se que a histórico-crítica traz, em seus pressupostos teóricos, a gênese de uma educação que considera o homem como ser multidimensional e, por esse motivo, será apresentada, neste artigo, como próximas aos ideais da educação integral.

Propõe-se, então, como objetivo para este texto, o resgate de algumas experiências de educação integral ao longo da História da Educação Brasileira, bem como apresenta de que maneira esse modelo educacional vem sendo discutido nos documentos elaborados pelo Ministério da Educação. Além disso, explicita e compreende os pressupostos teóricos, que embasam a concepção de educação integral, à luz da perspectiva histórico-crítica.

Para este estudo, utilizou-se a metodologia de pesquisa bibliográfica, por tratar-se de um tema que exige a análise de uma determinada concepção teórica, cujos entrelaçamentos se dão no bojo de reflexões e discussões com autores que se aproximam por terem o mesmo ideal de educação integral.

\section{Educação integral: uma política presente em algumas ideologias}

A proposição do modelo de educação integral perpassa momentos importantes da história humana em diversos contextos sociais. Coelho $(2009$, p. 85) afirma ser possível "dizer que, historicamente, as reflexões sobre uma formação mais completa remontam ao início da civilização humana e, com ela, perpassam matrizes ideológicas bem diferentes em termos político-filosóficos". Em seu artigo "História(s) da educa- 
ção integral", publicado em um número especial sobre educação integral da Revista Em Aberto, a autora traça uma linha temporal, destacando momentos históricos que tomaram para si a perspectiva de educação integral. Ela relata, nesse texto, que a ideia de uma educação mais ampla concebida a partir da formação do corpo e do espírito, já existia desde a Antiguidade, na chamada Paideia Grega, evoluindo junto com a humanidade com o objetivo de atender as necessidades de cada fase histórico-social.

O campo educacional, assim como outros, é bastante heterogêneo em suas manifestações sócio-históricas, pois depende da visão de mundo que embasa as ações de um determinado grupo social, gerando concepções ideológicas que apresentam pontos convergentes em alguns aspectos, mas também, grandes divergências em outros. Esses pontos de distanciamento provocam o desenvolvimento de novas ideologias para o trabalho com a educação, através do dinamismo das relações sociais, configurando um cenário de mudanças constantes das concepções educacionais já existentes, em busca de melhores condições de entendimento das próprias relações sócio-históricas desse contexto.

Pode-se, então, compreender a amplitude da concepção de educação integral em servir aos propósitos de ideologias com diferentes posicionamentos político-filosóficos, mas que se aproximam no ideal de desenvolvimento completo do ser humano.

No Brasil, a educação integral esteve presente nos ideais de diversos movimentos educacionais, demonstrando que coexistem posicionamentos político-filosóficos com pressupostos divergentes, mas que objetivam em comum uma formação multidimensional do humano. Conforme aponta o texto referência para o debate nacional sobre esse tema, elaborado pelo MEC,

\begin{abstract}
no Brasil, na primeira metade do século XX, encontramos investidas significativas a favor da Educação Integral, tanto no pensamento quanto nas ações de cunho educativo de católicos, de anarquistas, de integralistas e de educadores como Anísio Teixeira, que tanto defendiam quanto procuravam implantar instituições escolares em que essa concepção fosse vivenciada. No entanto, cabe ressaltar que eram propostas e experiências advindas de matrizes ideológicas bastante diversas e, por vezes, até contraditórias. (BRASIL, 2009d, p. 15)
\end{abstract}

De acordo com Coelho, nesse momento histórico, "coexistiam movimentos, tendências e correntes políticas dos mais variados matizes, discutindo educação; mais precisamente defendendo a educação integral, mas com propostas político-sociais e teórico-metodológicas diversas". (2009, p. 88). Nas primeiras décadas do século XX, com o movimento anarquista e os ideais da teoria libertária que eles defendiam, surge a ênfase na formação integral, propondo que o modelo escolar apresentasse objetivos que recaíssem "sobre a igualdade, a autonomia e a liberdade humana, em uma clara opção política emancipadora”. (BRASIL, 2009d, p. 15).

Kassick em seu artigo "Pedagogia libertária na história da educação brasileira”, afirma que o movimento libertário brasileiro foi influenciado pelos ideais pedagógicos de educação integral, propostos pelo francês Paul Robin, e também pelas ideias de ensino racional, difundidas pelo anarquista catalão Francisco Ferrer. São vertentes que se "complementam e correspondem a dois grandes enfoques eleitos pelos 
educadores da época como forma de romper com a educação classista que imperava". (KASSICK, 2008, p. 141). Nesse sentido, a proposta de educação integral, no modelo anarquista buscava proporcionar um desenvolvimento que contemplasse os aspectos físico, intelectual e moral, através de atividades que integrassem o trabalho manual e o intelectual, sendo, integral e racional ao mesmo tempo.

Durante o período dos anos 30 aos anos 60 do século XX, surgiu o movimento integralista, que defendia a educação integral com base nos aspectos espirituais, de nacionalismo cívico e de disciplina (BRASIL, 2009d, p. 15).

Tendo o educador Anísio Teixeira como seu principal precursor, o movimento chamado de Escola Nova ${ }^{1}$ buscava "desenvolver uma educação integral, provendo, de forma articulada, a educação física, moral e cívica, desenvolvendo, nos alunos, hábitos higiênicos, despertando o sentindo da saúde, a resistência e vitalidades físicas, a alegria de viver". (SAVIANI, 2010, p. 212). O que estava sendo proposto por Anísio era um

programa completo de leitura, aritmética e escrita, e mais ciências físicas e sociais, e mais artes industriais, desenho, música, dança e educação física. Além disso, desejamos que a escola eduque, forme hábitos, forme atitudes, cultive aspirações, prepare, realmente, a criança para a sua civilização - esta civilização tão difícil por ser uma civilização técnica e industrial e ainda mais difícil e complexa por estar em mutação permanente. E, além disso, desejamos que a escola dê saúde e alimento à criança, visto não ser possível educá -la no grau de desnutrição e abandono em que vive. (TEIXEIRA, 1959)

Significa considerar o ambiente escolar como um lugar onde todas as atividades (intelectuais, artísticas, profissionais, físicas e de saúde), desenvolvam o aspecto global do ser humano, consubstanciando uma formação completa.

Cavaliere destaca que o movimento escolanovista trouxe

novas ideias em educação que questionavam o enfoque pedagógico até então centrado na tradição, na cultura intelectual e abstrata, na autoridade, na obediência, no esforço e na concorrência. Para os reformistas, a educação deveria assumir-se como fator constituinte de um mundo moderno e democrático, em torno do progresso, da liberdade, da iniciativa, da autodisciplina, do interesse e da cooperação. As reformas nas instituições escolares visavam à retomada da unidade entre aprendizagem e educação, rompida a partir do início da era moderna, pela própria escolarização, e buscavam religar a educação à “vida”. (2002a, p. 252)

Esse movimento teve seu embasamento assentado no pensamento de Dewey $^{2}$, de orientação pragmatista, cujas obras influenciaram substancialmente as ações do educador brasileiro Anísio Teixeira, que, na década de 1950, implantou o Centro Educacional Carneiro Ribeiro em Salvador, na Bahia. Nesse Centro, de acordo com Coelho, "encontramos as atividades, historicamente entendidas como escolares, sendo trabalhadas nas Escolas-Classe, bem como outra série de atividades acontecen- 
do no contraturno escolar, no espaço o qual o educador denominou de "Escola-Parque" (2009, p. 89). Na década seguinte, outros centros dessa mesma natureza foram implantados também na cidade de Brasília.

Tenório e Schelbauer explicitam que o reflexo da influência dos ideais de Anísio Teixeira para uma educação integral de qualidade pode ser visto por meio de outros projetos como o dos CIEPs, que, na década de 1980, foram propostos pelo educador Darcy Ribeiro no Rio de Janeiro. Esses Centros Integrados de Educação Pública também propunham o trabalho pedagógico a partir da concepção de educação integral. De acordo com o documento elaborado pelo MEC, "arquitetados por Oscar Niemeyer, foram construídos aproximadamente quinhentos prédios escolares durante os dois governos de Leonel Brizola, no Rio de Janeiro, cuja estrutura permitia abrigar o que se denominava como Escola Integral em horário integral". (2009d, p. 16).

Buscando incentivar os debates acerca dessa temática, o MEC publicou, em 2009, uma trilogia ${ }^{3}$ que visa também orientar a implantação de políticas educacionais. Publicada em conjunto com a SECAD, aborda, de forma abrangente, os principais pontos que devem ser esclarecidos sobre educação e tempo integral, objetivando "animar o debate e a construção de um paradigma contemporâneo de Educação Integral, que possa constituir-se como legado qualificado e sustentável" (BRASIL, 2009d, p. 7). São três cadernos, assim apresentados:

O primeiro intitula-se Gestão Intersetorial no Território e trata dos marcos legais do Programa Mais Educação, das temáticas Educação Integral e Gestão Intersetorial, da estrutura organizacional e operacional do Programa Mais Educação, dos projetos e programas ministeriais que o compõem e de sugestões para procedimentos de gestão nos territórios. O segundo caderno, Educação Integral, apresenta o texto referência sobre Educação Integral para o debate nacional. O texto foi produzido pelo Grupo de Trabalho composto por gestores e educadores municipais, estaduais e federais, representantes da União Nacional dos Dirigentes Municipais de Educação (UNDIME), do Conselho Nacional dos Secretários de Educação (CONSED), da Confederação Nacional dos Trabalhadores em Educação (CNTE), da Associação Nacional pela Formação de Profissionais da Educação (ANFOPE), de Universidades e de Organizações não-governamentais comprometidas com a educação. Esse Grupo de Trabalho foi convocado pelo Ministério da Educação, sob coordenação da SECAD. O terceiro caderno, Rede de Saberes Mais Educação, sugere caminhos para a elaboração de propostas pedagógicas de Educação Integral por meio do diálogo entre saberes escolares e comunitários. Esses caminhos são representados na forma de Mandalas de Saberes para incorporar as diversas realidades territoriais brasileiras. (BRASIL, 2009d, p. 6-7)

De acordo com o primeiro caderno dessa trilogia, a educação integral sintetiza um ideal de educação pública nacional e democrática, materializado, através de um posicionamento diferenciado acerca dos avanços, limites e possibilidades de um olhar mais completo sobre a formação do aluno através do trabalho escolar. Nesse sentido, o saber objetivo é organizado em "práticas, habilidades, costumes, crenças e valores que estão na base da vida cotidiana e que, articulados ao saber acadêmico, constituem o currículo necessário à vida em sociedade" (BRASIL, 2009d, p. 27). 
De acordo com essa trilogia,

a Educação Integral exige mais do que compromissos: impõe também e principalmente projeto pedagógico, formação de seus agentes, infraestrutura e meios para sua implantação. Ela será o resultado dessas condições de partida e daquilo que for criado e construído em cada escola, em cada rede de ensino, com a participação dos educadores, educandos e das comunidades que podem e devem contribuir para ampliar os tempos e os espaços de formação de nossas crianças, adolescentes e jovens na perspectiva de que o acesso à educação pública seja complementado pelos processos de permanência e aprendizagem. (Id., Ib., p. 6)

Assim, as "condições de partida" constroem a base para a práxis de qualquer modelo educacional, sendo, portanto, essenciais no processo de implantação de políticas educacionais. Tais condições dependerão também da ação dos agentes de cada contexto, os quais devem ser conhecedores dos pressupostos que embasam a concepção de educação integral, das orientações oficiais sobre sua implantação, bem como das características peculiares à realidade escolar. Neste sentido, a proposta de uma formação que concebe o homem como um ser multidimensional e sócio-cultural, se aproxima do ideal de educação pública democrática, por ser um condicionante para o próprio desenvolvimento humano, potencializado nas relações de ensino e de aprendizagem mediadas pelo saber objetivo durante a etapa da Educação Básica. Segundo o documento,

pode-se afirmar que a Educação Integral é fruto de debates entre o poder público, a comunidade escolar e a sociedade civil, de forma a assegurar o compromisso coletivo com a construção de um projeto de educação que estimule o respeito aos direitos humanos e o exercício da cidadania. (BRASIL, Ib., p. 27)

Essa proposta de educação pressupõe a ampliação do espectro de atuação da escola, conforme aponta um estudo de mapeamento das experiências de educação integral, em tempo integral na Educação Brasileira, realizado pelo MEC em conjunto com algumas universidades ${ }^{4}$, publicada em 2009. De acordo com esse estudo, tal ampliação

assume novas dimensões de formação na perspectiva de uma educação integral que contemple não apenas os saberes escolares clássicos, mas também, diferentes manifestações artísticas, culturais, esportivas, intelectuais, ligadas à comunidade ou capazes de enriquecê-la. (Id., Ib., p. 129)

A educação integral deve promover uma aprendizagem completa e consubstanciada por atos educativos intencionais que promovam "experiências capazes de desenvolver habilidades cognitivas e intelectuais, afetivas, físicas, éticas e sociais" (CENPEC, 2011, p. 26), as quais deverão ser expressas e regulamentadas por meio do projeto político pedagógico, que deve prever, entre outros aspectos, as "mediações e compartilhamentos entre diversos atores, instituições e territórios de vida, buscando a circulação de saberes e vivências nos espaços educativos". (Id., Ib., p. 26).

Cavaliere afirma que essas práticas compõem "uma concepção educacional democraticamente elaborada, explicita e publicamente compartilhada", pelas relações 
político-sociais existentes entre as diversas realidades sócio-históricas, determinadas por seu acervo cultural. (2002a, p. 266).

Assim, entende-se que esse modelo educacional é democrático por seu caráter integrador das multidimensões humanas, potencializadas nas intersecções das relações sociais vivenciadas no interior da escola e da sociedade como um todo, sem excluir nenhum indivíduo das novas gerações, não importando a qual grupo social pertença. Esse aspecto igualitário responsabiliza toda a sociedade pelo processo de educar integralmente e, na união desses esforços, nascem práticas educativas minimizadoras das desigualdades sociais, transcendendo uma visão assistencialista comumente relacionada à educação na atualidade.

No sentido de orientar a práxis educativa, faz-se necessário que o Projeto Político Pedagógico de uma escola de educação integral apresente uma concepção de educação que sirva como pano de fundo para suas atividades com os alunos. Dentre outras perspectivas educacionais, este estudo propõe a interface da perspectiva histórico-crítica com os pressupostos da educação integral.

\title{
Educação integral e a perspectiva histórico-crítica
}

A perspectiva histórico-crítica está contida no cenário das propostas educacionais denominadas críticas, cuja gênese encontra-se

\begin{abstract}
no conjunto das elaborações teóricas de Marx e Engels, tratando-se, assim, de elaborações que, ao analisarem a origem e o desenvolvimento histórico do sistema capitalista, bem como as condições de vida por ele engendradas, revelam que a sociedade atual se estrutura sobre relações de dominação entre grupos e classes sociais. (DUARTE, 1993, p. 8, apud SCÁLCON, 2002, p. 67)
\end{abstract}

Além de seu caráter crítico, a perspectiva em questão é também histórica, uma vez que compreende a educação à luz do desenvolvimento histórico da sociedade e do ser humano. Scalcon afirma que, conforme Oliveira,

essa concepção histórica do ser humano está diretamente ligada com o processo de apropriação do conhecimento, enquanto um processo/produto cultural que possibilita ao homem conhecer sua realidade e nela atuar enquanto sujeito histórico-social. [...] (OLIVEIRA, 1994, p. 124, apud SCALCON, 2002, p. 3)

Com esse pano de fundo, o educador Dermeval Saviani, estruturou sua teoria educacional denominada histórico-crítica, que está em processo de desenvolvimento desde 1984 no cenário das teorias educacionais brasileiras. Está apoiada no pensamento marxista e busca compreender os caminhos percorridos pela educação brasileira como determinantes para o cenário atual, além de objetivar "corrigir distorções que acarretaram e acarretam o quadro sociocultural da realidade brasileira e cuja marca é a discriminação e a 'desominização' do homem” (SCALCON, 2002, p. 90). De acordo com Saviani, a teoria histórico-crítica relaciona-se 


\begin{abstract}
com a realidade escolar nas suas raízes históricas. Sabe-se que o que caracteriza o homem é o fato de ele necessitar continuamente produzir a sua existência. Em outros termos, o homem é um ser natural peculiar distinto dos demais seres naturais, pelo seguinte: enquanto estes em geral - os animais inclusive - adaptam-se à natureza e, portanto, têm já garantidas, pela própria natureza, suas condições de existência, o homem precisa adaptar a natureza a si, ajustando-a, segundo as suas necessidades. (SAVIANI, 2008, p. 94 e 95)
\end{abstract}

Desta forma, o homem é distinguido no mundo, pois precisa, através do seu próprio trabalho, garantir um lugar em seu contexto sócio-histórico, ajustando o espaço natural as suas necessidades. Esse agir, através do trabalho, é o que marca o desenrolar da história humana e também de sua cultura, ao longo do tempo. Para Saviani, a gênese da educação está nesse processo de elaboração da história e da cultura humana por meio de ações sobre a natureza, o que entrelaça os conhecimentos já produzidos pelo homem, com o próprio ato de viver, de se tornar homem e de se educar para uma vida plena.

A teoria histórico-crítica ressalta a função e a natureza da educação como aspectos que justificam a importância de sua existência e das instituições transmissoras de conhecimento - escolas. Nela, a educação tem natureza de trabalho não-material, uma vez que utiliza ideias, conceitos, valores, símbolos, hábitos, atitudes, entre outros para a realização de sua função, que é a de sistematizar e socializar os saberes objetivos produzidos e acumulados pela humanidade. As novas gerações têm contato com esse saber objetivo e sistematizado através da escola, que procura realizar a transmissão do conhecimento, por meio da atividade mediadora que é inerente à prática educativa, uma vez que influencia a realidade na qual está inserida e é também por ela influenciada (Idem, Ibidem, p.4). Além disso, essa prática é determinante para que o sujeito possa participar de sua sociedade, ao menos, de forma decente, podendo ter acesso aos direitos mínimos que lhe permitam ter uma vida digna.

Por "compreender a educação como setor fundamental para todo o desenvolvimento que preconize o homem como sujeito central" (Idem, Ibidem, p. 92), a teoria histórico-crítica prevê a ele um desenvolvimento social global, "dependente da educação, ao mesmo tempo em que a educação é entendida como condicionada à realidade, principalmente por sua estrutura política" (Idem, Ibidem). Para isso, é preciso considerar o homem na inteireza de suas dimensões física, biológica, psicológica e cultural, sendo, por essa configuração, o agente dentro do processo de transformação do meio no qual vive, ao mesmo tempo em que é transformado por ele. Esse caráter de mediação e de integralidade tanto do ser humano, quanto de sua realidade composta pelas relações sociais e suas contradições, comportam os ideais da educação integral.

A concretude desses ideais está presente quando se compreende a prática da teoria educacional histórico-crítica, explicitada a partir de cinco passos definidos por Saviani como: prática social, problematização, instrumentalização, catarse e prática social novamente. A prática social refere-se ao relacionamento entre os agentes do cenário escolar: professor que é visto como alguém que aprende ao mesmo tempo em que ensina; aluno, que é aquele que tem um nível de conhecimento sincrético ${ }^{5}$ ainda desarticulado. Essas relações, obviamente, estão inseridas em um contexto social, que apresenta, em escala menor, os problemas oriundos da sociedade macro. Isso requer atividades de questionamento, de análise crítica, de avaliação e de busca de soluções 
práticas para os problemas identificados. Após esse contato teórico, emerge a necessidade de busca por instrumentos que sirvam de apoio para a resolução do problema apontado, a partir da integração entre a teoria e a prática, que dará origem ao processo de catarse, o qual, de acordo com Saviani, trata-se do passo mais importante dentro do processo educativo, por ser o momento em que o sujeito constitui sua autoconsciência, passando do movimento da síncrese para a síntese. Tendo essa consciência de si próprio, dentro de sua realidade social, o aluno passa a ter uma visão mais organizada e mais precisa dos problemas e da prática social que está posta como pano de fundo para os conteúdos sistematizados pela escola e socializados de forma mediada através da educação (integral). A prática social é, portanto, o ponto de partida e o ponto de chegada nesse processo, tendo importante destaque pelo seu caráter dialético com a educação (Idem, Ibidem, pp. 123 a 125).

Considerando o aluno como um ser global, a perspectiva histórico-crítica concebe a sistematização e a socialização do conhecimento a partir das relações entre a teoria e a prática, em um modelo educacional que chama para si a concepção de educação integral, ressaltando "a especificidade da escola e a importância do trabalho escolar como elementos necessários ao desenvolvimento cultural, que concorrem para o desenvolvimento humano em geral" (SAVIANI, 2008, p. 103).

\section{Considerações finais}

Entender a realidade social e posicionar-se de maneira crítica dentro dela é um dos pressupostos que fazem da educação integral uma concepção ideal para desenvolver o ser humano em todos os seus aspectos. Aliada a isso, está a teoria históricocrítica da educação como pano de fundo desse cenário, que concebe o homem de uma forma inteira, imerso em um contexto histórico-social, no qual ele é agente consciente e crítico de sua própria realidade.

Compreender a articulação entre essas concepções permite entender a educação sob outro enfoque, mais abrangente e mais justo com o desenvolvimento do homem social e cultural, bem como com a satisfação de suas necessidades mais latentes, além de ser uma tentativa minimizadora das diferenças sociais que existem na sociedade capitalista. Certamente, essa articulação precisa de uma ampliação de jornada escolar para tornar-se mais efetiva, segura e abrangente. Sem, contudo, tornarse apenas um lugar desorganizado, onde os alunos fiquem por mais tempo. Não é algo que possa ser realizado em curto prazo ou de maneira superficial, pois implica ações de profunda mudança do ideário de educação e de suas práticas.

Assim, antes da implementação dessas concepções articuladas entre si, é necessário que se compreenda muito bem seus pressupostos para que a prática traga benefícios e mudanças para a própria realidade social. 


\section{Referências}

BRASIL. Série Mais Educação. Educação Integral. Texto referência para o debate nacional. Brasília, 2009d.

CAVALIERE, A. M. Educação integral: uma nova identidade para a escola brasileira? In: Educação \& Sociedade., Campinas, vol. 23, n. 81, p. 247-270, dez. 2002a.

CENPEC. Tendências para a educação integral. São Paulo: Fundação Itaú Social, 2011.

COELHO, L. M. C. da C. História(s) da educação integral. In: Em Aberto, Brasília, v. 22, n. 80, p. 83-96, abr. 2009.

KASSICK, C. N. Pedagogia libertária na história da educação brasileira. Revista HISTDBR Online, Campinas, n. 32, p. 136 - 149, dez. 2008.

SAVIANI, D. História das ideias pedagógicas no Brasil. Campinas, SP: Autores Associados, 2010.

. Pedagogia Histórico-Crítica. Campinas, São Paulo. Autores Associados, 2008.

SCALCON, S. À procura da unidade psicopedagógica - articulando a psicologia históricocultural com a pedagogia histórico-crítica. Campinas/SP. Autores Associados, 2010.

TEIXEIRA, A. Centro Educacional Carneiro Ribeiro. Revista Brasileira de Estudos Pedagógicos. Rio de Janeiro, vol. 31, jan./mar., 1959. Disponível em: <http://www.bvanisioteixeira. ufba.br/artigos/cecr.htm>. Acesso em: 05 jan. 2012.

TENÓRIO, A. F.; SCHELBAUER, A. R. A defesa pela educação integral nas obras de Anísio Teixeira. Disponível em: <http://www.histdbr.fae.unicamp.br/acer_histdbr/jornada/ jornada7/_GT1\%20PDF/A\%20DEFESA\%20PELA\%20EDUCA\%C7\%C30\%20INTEGRAL\%20NA\%20OBA\%20DE\%20AN\%CDSIO.pdf>. Acesso em: 13 jan. 2013.

\section{Notas}

1 "O movimento reformador, do início do século XX, refletia a necessidade de se reencontrar a vocação da escola na sociedade urbana de massas, industrializada e democrática. De modo geral, para a corrente pedagógica escolanovista a reformulação da escola esteve associada à valorização da atividade ou experiência em sua prática cotidiana. $\mathrm{O}$ entendimento da educação como vida, e não como preparação para a vida, foi a base dos diversos movimentos que a formaram”. (CAVALIERE, 2002a, p. 251).

2 "Para compreender o pensamento de Dewey e, especialmente, sua orientação pragmatista, é preciso partir do significado que atribui à "experiência”. Esta é, segundo ele, a própria vida, não existindo separação entre ela e natureza. A experiência é um modo de existência da natureza. No âmbito da vida humana, a experiência gera modificações de comportamento, ou seja, gera aprendizagens, mais ou menos conscientes, que modificam as experiências subsequentes. Em outras palavras, experiências ensejam mudanças que são transformações mútuas nos elementos que agem uns sobre os outros. Por isso, o autor considera que experiência é aprendizagem, é transformação, é um modo de existência, não sendo possível dissociar tais elementos. A vida humana é uma teia de experiências e, portanto, de aprendizagens variadas". (CAVALIERE, 2002a, p. 257-258).

${ }^{3}$ Este estudo não tomará como objeto de análise tal trilogia, mas sim a apresentará com o objetivo de demonstrar que o Ministério da Educação vem propondo discussões e reflexões sobre essa temática.

${ }^{4}$ UFRPR, UNB, INIRIO, UFRJ, UERJ, UFMG e ULBRA.

${ }^{5}$ Conhecimentos de diversas áreas. 
* Professora Diretora Pedagógica em um Colégio da rede particular de ensino no interior do estado de São Paulo, Indaiatuba, São Paulo - Brasil.

** Professora Doutora da Pontifícia Universidade Católica de Campinas, Centro de Ciências Sociais Aplicadas. Campinas, São Paulo - Brasil.

\section{Correspondência}

Rita de Cássia Ventura Pattaro - Colégio Meta, Rua Hermínio Steffen, 96, Jardim Regina, CEP: 13348883 - Indaiatuba, São Paulo - Brasil.

E-mail: ritapattaro@hotmail.com; veris@puc-campinas.edu.br

Recebido em 20 de fevereiro de 2013

Aprovado em 26 de agosto de 2013 
